\title{
Impact of Previous Angina on Clinical Outcomes in ST-Elevation Myocardial Infarction Underwent Percutaneous Coronary Intervention
}

\author{
Xiongyi Han, Myung Ho Jeong*, Jumin Won, Yongcheol Kim, Min Chul Kim, Doo Sun Sim, \\ Young Joon Hong, Ju Han Kim, and Youngkeun Ahn \\ The Heart Center and Cardiovascular Convergence Research Center of Chonnam National University Hospital, Gwangju, Korea
}

The present study sought to assess the impact of previous angina symptoms on real world clinical outcomes in patients with ST-elevation myocardial infarction (STEMI) who had undergone successful percutaneous coronary interventions using drug-eluting stents (DES). Patients were selected from 13,650 consecutive patients enrolled in the Korea Acute Myocardial Infarction-National Institute of Health (KAMIR-NIH) registry. A total of 5167 STEMI patients were divided into a previous-angina group $(\mathrm{n}=$ $1129)$ and a control group $(n=4038)$. Major adverse cardiac and cerebrovascular events (MACCEs) that included all-cause death, recurrent myocardial infarction (re-MI), repeat PCI, coronary artery bypass graft (CABG), cerebrovascular accident (CVA). Among the 5167 patients with STEMI, MACCEs had occurred in 168 patients in the previousangina group (14.9\%) and 726 patients in the control group (18.0\%) (HR, 0.76, 95\% CI, $0.60-0.96, p=0.019)$ at the two-year (800-day) for clinical outcomes. Previous angina was associated with better clinical outcomes with respect to all-cause death (HR, 0.65, 95\% CI, 0.44-0.96, $\mathrm{p}=0.029$ ) and cardiac death (HR, 0.52, 95\% CI, 0.31-0.84, $\mathrm{p}=0.008$ ). Previous angina was a negative risk factor for adverse cardiac events. A previous history of angina predisposes a patient to a favorable outcome after acute myocardial infarction (AMI) in patients with DES implantation.

Key Words: Ischemic Preconditioning; Myocardial Infarction; Angina Pectoris; DrugEluting Stents

This is an Open Access article distributed under the terms of the Creative Commons Attribution Non-Commercial License (http://creativecommons.org/licenses/by-nc/4.0) which permits unrestricted non-commercial use, distribution, and reproduction in any medium, provided the original work is properly cited.

\section{Article History:}

Received December 19, 2019

Revised January 9, 2020

Accepted January 20, 2020

\section{Corresponding Author:}

Myung Ho Jeong

Principal Investigator of Korea Acute Myocardial Infarction Registry, The Heart Research Center, Chonnam National University Hospital, 671 Jaebong-ro, Dong-gu, Gwangju 61469, Korea Tel: +82-62-220-6243

Fax: +82-62-228-7174

E-mail: myungho@chollian.net

\section{INTRODUCTION}

Ischemic preconditioning (IPC) is an experimental technique for generating loss of oxygen and blood supply in many types of tissues. Clinically, we can use the previous angina to infer about IPC phenomena. In animal studies, inducing sub-lethal ischemia before ischemic insult has been associated with a smaller infarct size. ${ }^{1} \mathrm{~A}$ transient episode of ischemia before long-term ischemic injury was found to improve prognosis. ${ }^{2}$ In humans, patients with angina pectoris and acute myocardial infarction (AMI) have a smaller infarct size after thrombolytic therapy, and inhospital outcomes are superior compared to patients without pre-infarction angina. ${ }^{3}$ Furthermore, another study reported that patients with an ischemic symptom in the 90 days before AMI had a higher mortality rate than patients without any occurrences. ${ }^{4}$ However, most studies report a better prognosis for Ischemic preconditioning (IPC), ${ }^{5,6}$ and a number of studies have found that IPC reduced infarct size enhanced recovery of cardiac function and improved clinical outcomes in the fibrinolytic era. In the 1990s, there were more studies on IPC, but it has only been studied rarely in recent years, in the drug-eluting stent (DES) era. DESs reduce the incidence of restenosis compared to baremetal stents (BMSs), thereby reducing target vessel revascularization. ${ }^{7}$ In the thrombolysis age, there are papers related to this, but in the current 2nd-generation age, there is a little such research.

There is no clear consensus in this area, and some research results are different between Asian and Western 
countries. ${ }^{8}$ The aim of this observational study was to investigate the prevalence, characteristics, and clinical outcomes in ST-elevation myocardial infarction (STEMI) patients with previous angina treated by DES. The main point of this paper is to see if there is a difference in clinical outcomes according to the previous angina.

\section{MATERIALS AND METHODS}

\section{Study population}

The study population was derived from participants in the Korean Acute Myocardial Infarction Registry-National Institutes of Health (KAMIR-NIH), collected between October 2011 and December 2015. KAMIR-NIH is a prospective, open, online, multi-center data collection registry from 20 tertiary hospitals in South Korea with the capacity to perform percutaneous coronary intervention (PCI), aimed at capturing real-life treatment practices and outcomes in patients with AMI. ${ }^{9}$ Details of the registry can be found on the KAMIR website. We evaluated a total of 13,650 patients from the KAMIR-NIH. Of those, we excluded patients with unstable angina pectoris (UAP) or non-ST-elevation myocardial infarction (NSTEMI) $(n=6,473)$, patients lost at follow-up $(n=1,143)$, patients with no or failed PCI $(\mathrm{n}=505)$ or patients subjected to implantation of BMSs $(\mathrm{n}=362)$. Finally, a total of 5,167 STEMI patients in whom DESs were implanted were enrolled. They were divided into a previous-angina group $(n=1,129)$ and a control group without previous angina $(n=4,038)$ (Fig. 1). We compared baseline clinical characteristics, laboratory results, medical treatment, and clinical outcomes at the 2-year (800-day) follow-up. All patients had completed the 2-year outcome by interview, chart review or phone call.

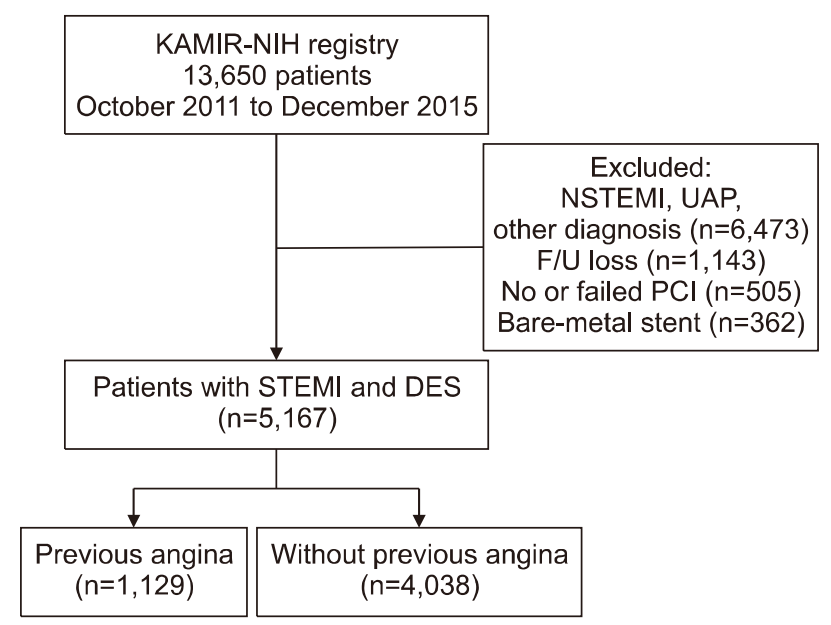

FiG. 1. Flow chart of study population. DES: drug-eluting stent, KAMIR-NIH: Korean Acute Myocardial Infarction RegistryNational Institutes of Health, NSTEMI: non-ST-elevation myocardial infarction, PCI: percutaneous coronary intervention, STEMI: ST-elevation myocardial infarction, UAP: unstable angina pectoris.

\section{Definition of previous angina}

Previous angina was defined as chest pain at any time prior to AMI, which was unstable under very frequent conditions and occurred within one month by reducing fatigue, resting angina or new angina. ${ }^{5}$

\section{Study endpoint}

The endpoint of the study was designated as the clinical events at 2-year follow-up, defined as all-cause death (cardiac death, non-cardiac death), recurrent myocardial infarction (re-MI), repeat PCI [target lesion revascularization (TLR), target vessel revascularization (TVR)], coronary artery bypass graft (CABG), cerebrovascular accident (CVA), major adverse cardiac and cerebrovascular events (MACCE: allcause death, re-MI, re-PCI, CABG and CVA).

\section{Statistical analysis}

All continuous variables were expressed as means with standard deviations (SDs). All categorical variables were reported as numbers with percentages. Continuous variables were compared using an unpaired t-test or the MannWhitney U test, as appropriate. Categorical variables were analyzed using a chi-square test or Fisher's exact test. To adjust for more accurate results, we tested all available variables that could be of potential relevance, such as previous angina, old age ( $\geq 65$ years), male sex, high heart rate ( $>100$, beat/min), hypertension, low systolic blood pressure $(\mathrm{SBP}<90, \mathrm{mmHg})$, low diastolic blood pressure (DBP $<60$, $\mathrm{mmHg}$, diabetes and dyslipidemia, low glomerular filtration rate $(\mathrm{GFR} \leq 60, \mathrm{~mL} / \mathrm{min})$, history of heart failure or CVA, low left ventricular ejection fractions (LVEFs $<40 \%$ ), high Killip classes (III/IV), smoking, low hemoglobin $(<10$, $\mathrm{g} / \mathrm{dL}$ ), high triglycerides ( $\geq 150, \mathrm{mg} / \mathrm{dL})$, low high-density lipoprotein (HDL) cholesterol $(\leq 40, \mathrm{mg} / \mathrm{dL})$ and high lowdensity lipoprotein (LDL) cholesterol ( $\geq 70, \mathrm{mg} / \mathrm{dL})$ and high $\mathrm{HbA1c}(>6.5 \%)$, door-to-balloon time ( $\geq 90$, $\mathrm{min})$, bad final thrombolysis in myocardial infarction (TIMI) flow (0/1), and multivessel disease. To investigate differences in survival times between the two groups, the risk of MACCE at follow-up was assessed for the two groups using the Kaplan-Meier method. In addition, we used a Cox proportional hazards regression model to regress survival on an indicator variable and evaluated the hazard ratio of clinical outcomes to compare the two groups. To identify significant predictors of MACCE following either previous angina or no previous angina, we screened for all predictors that might affect prognosis and performed regression for each potential clinical value using univariate modeling. We entered significant variables with a p-value $<0.1$ in univariate analysis into a multivariate Cox regression model. The adjusted survival analysis and hazard ratios (HRs) and the $95 \%$ confidence intervals (CIs) between the two groups were obtained by this multivariate analysis using COX regression modeling.

All analyses were two-tailed, and a $\mathrm{p}$ value $<0.05$ was considered significant. All statistical analyses were performed using SPSS for Windows software (ver. 25.0; SPSS 
Inc., Chicago, IL, USA).

\section{RESULTS}

\section{Baseline clinical and laboratory characteristics}

Baseline clinical and laboratory characteristics are shown in Table 1. The mean age of the pre-angina group was similar with the control group $(62.82 \pm 12.20$ vs $62.05 \pm 12.56$ years, $\mathrm{p}=0.066$ ). The proportions of males in the two groups were $76.3 \%$ and $79.8 \%$, respectively. SBP and DBP, heart rate, history of MI, the levels of HDL cholesterol, and hypersensitive C-reactive protein were higher patients in the previous angina group than in the control group. In con- trast, the proportion of current smokers, the LVEFs, white blood cells, triglycerides, and glucose were higher in the control group than in the pre-angina group. Additionally, the body mass index, the incidence of dyslipidemia and heart failure, and patients in Killip classes III/IV, over the age of 65 years, the incidence of hypertension, diabetes mellitus, and laboratory findings showed that the numbers of and the levels of hemoglobin, total cholesterol, LDL cholesterol, creatine kinase-myocardial band isoenzyme, creatinine, troponin-I, and HbA1c were similar between two groups.

TABLE 1. Baseline clinical and laboratory characteristics of patients in the two groups

\begin{tabular}{|c|c|c|c|}
\hline Variables & Pre-angina $(\mathrm{n}=1129)$ & No-pre-angina $(\mathrm{n}=4038)$ & p-value \\
\hline \multicolumn{4}{|l|}{ Demographics } \\
\hline Age, mean (SD), years & $62.82 \pm 12.20$ & $62.05 \pm 12.56$ & 0.066 \\
\hline Age $\geq 65$ & $503(44.6)$ & $1747(43.3)$ & 0.440 \\
\hline Male sex & $861(76.3)$ & $3221(79.8)$ & 0.011 \\
\hline BMI, mean (SD), kg/m² & $23.99 \pm 3.24$ & $24.13 \pm 3.19$ & 0.194 \\
\hline \multicolumn{4}{|l|}{ Cardiovascular risk factors (\%) } \\
\hline Hypertension & $519(46.0)$ & $1852(45.9)$ & 0.950 \\
\hline Diabetes mellitus & $289(25.6)$ & $970(24.0)$ & 0.275 \\
\hline Insulin-treated DM & $22(1.9)$ & $65(1.6)$ & 0.434 \\
\hline Dyslipidemia & $120(10.6)$ & $447(11.1)$ & 0.675 \\
\hline Current smoking & $669(40.7)$ & $2568(63.6)$ & 0.008 \\
\hline \multicolumn{4}{|l|}{ Medical history (\%) } \\
\hline Myocardial infarction & $81(7.2)$ & $156(3.9)$ & $<0.001$ \\
\hline Heart failure & $5(0.4)$ & $26(0.6)$ & 0.439 \\
\hline Cerebrovascular accident & $53(4.7)$ & $204(5.1)$ & 0.625 \\
\hline \multicolumn{4}{|l|}{ Vital signs on admission } \\
\hline $\mathrm{SBP}$, mean $(\mathrm{SD}), \mathrm{mmHg}$ & $128.96 \pm 27.86$ & $125.18 \pm 31.44$ & $<0.001$ \\
\hline $\mathrm{DBP}$, mean $(\mathrm{SD}), \mathrm{mmHg}$ & $79.00 \pm 18.01$ & $76.51 \pm 19.99$ & $<0.001$ \\
\hline $\mathrm{HR}$, mean (SD), beat/min & $78.39 \pm 19.00$ & $76.46 \pm 20.43$ & 0.004 \\
\hline Killip classification III/IV (\%) & $150(13.3)$ & $583(14.4)$ & 0.327 \\
\hline LVEF, (\%) & $49.20 \pm 10.13$ & $50.63 \pm 10.28$ & $<0.001$ \\
\hline \multicolumn{4}{|l|}{ Laboratory findings } \\
\hline $\mathrm{WBC}, 10^{3} / \mathrm{uL}$ & $11.14 \pm 3.62$ & $11.62 \pm 4.15$ & $<0.001$ \\
\hline $\mathrm{Hb}, \mathrm{g} / \mathrm{dL}$ & $14.22 \pm 1.96$ & $14.26 \pm 1.93$ & 0.557 \\
\hline Total cholesterol, mg/dL & $181.99 \pm 43.43$ & $182.80 \pm 44.31$ & 0.588 \\
\hline Triglycerides, mg/dL & $134.27 \pm 112.30$ & $143.36 \pm 123.57$ & 0.032 \\
\hline HDL-cholesterol, mg/dL & $43.38 \pm 11.37$ & $42.41 \pm 12.39$ & 0.022 \\
\hline LDL-cholesterol. mg/dL & $114.40 \pm 37.86$ & $116.25 \pm 39.61$ & 0.189 \\
\hline Glucose & $172.56 \pm 78.13$ & $178.31 \pm 78.16$ & 0.032 \\
\hline Creatinine, $\mathrm{g} / \mathrm{dL}$ & $0.99 \pm 0.78$ & $1.03 \pm 0.72$ & 0.070 \\
\hline $\mathrm{Hs}-\mathrm{CRP}, \mathrm{mg} / \mathrm{dL}$ & $1.85 \pm 5.30$ & $1.15 \pm 3.48$ & $<0.001$ \\
\hline Peak CK-MB, ng/mL & $161.07 \pm 194.53$ & $173.00 \pm 190.84$ & 0.066 \\
\hline Peak Troponin-I, ng/mL & $80.04 \pm 177.32$ & $77.69 \pm 136.74$ & 0.669 \\
\hline $\mathrm{HbA1c},(\%)$ & $6.48 \pm 1.53$ & $6.46 \pm 1.51$ & 0.711 \\
\hline PRU & $183.58 \pm 106.41$ & $180.82 \pm 108.89$ & 0.685 \\
\hline ARU & $450.31 \pm 72.55$ & $458.58 \pm 76.56$ & 0.131 \\
\hline
\end{tabular}

Data are expressed as No. (\%) unless otherwise indicated.

ARU: aspirin reaction units, BMI: body mass index, CK: creatine kinase, DBP: diastolic blood pressure, DM: Diabetes mellitus, HDL: high-density lipoprotein, HR: heart rate, Hb: hemoglobin, hs-CRP: high-sensitivity C-reactive protein, LDL: low-density lipoprotein, LVEF: left ventricular ejection fraction, PRU: P2Y12 reaction units, SBP: systolic blood pressure, STEMI: ST-elevation myocardial infarction, WBC: white blood cell. 
2. Coronary angiographic and medication characteristics

The characteristics of coronary angiography and medication are shown in Table 2 . The percentage frequencies of left main (LM) $(2.1 \%$ vs. $1.4 \%)$ and left anterior descending (LAD) (56.0\% vs. $51.4 \%$ ) coronary artery lesions were higher in the previous angina group than in the control group, but the percentage frequencies of left circumflex (LCX) (8.2\% vs. $9.0 \%)$ and right coronary artery (RCA) $(33.7 \%$ vs. $38.2 \%$ ) lesions were lower in the previous angina group than in the control group ( $\mathrm{p}=0.008)$. Infarct-related artery (IRA) stent diameter was lower in the previous angina group than in the control group $(3.15 \pm 0.43 \mathrm{~mm}$ vs. $3.18 \pm$ $0.42 \mathrm{~mm}, \mathrm{p}=0.081$ ) and stent length was similar in the two groups $(25.59 \pm 7.22 \mathrm{~mm}$ vs. $25.28 \pm 7.14 \mathrm{~mm}, \mathrm{p}=0.190)$. With respect to medicine usage, apart from clopidogrel $(65.4 \%$ vs. $59.2 \%, \mathrm{p}<0.001)$, prasugrel $(11.2 \%$ vs. $15.8 \%, \mathrm{p}<0.001)$, and statins (94.9\% vs. $91.7 \%, \mathrm{p}<0.001)$, the usage of other drugs, such as aspirin (100\% vs $99.8 \%)$, ticagrelor $(23.4 \%$ vs. $25.0 \%)$, calcium channel antagonists (3.7\% vs. $3.1 \%)$, angiotensin converting enzyme inhibitors/angiotensin II receptor blockers (ACEIs/ARBs) (79.8\% vs. $78.9 \%$ ), and beta-blockers ( $86.7 \%$ vs. $86.3 \%$ ) was not significantly different between the two groups.

TABLE 2. Characteristics of coronary angiography and medication of the two groups

\begin{tabular}{|c|c|c|c|}
\hline Variables & $\begin{array}{c}\text { Pre-angina } \\
(\mathrm{n}=1129)\end{array}$ & $\begin{array}{c}\text { No-pre-angina } \\
\quad(\mathrm{n}=4038)\end{array}$ & $p$-value \\
\hline Infarct-related artery (\%) & & & 0.008 \\
\hline Left anterior descending & $632(56.0)$ & $2076(51.4)$ & \\
\hline Left circumflex & $93(8.2)$ & $362(9.0)$ & \\
\hline Right coronary & $380(33.7)$ & $1543(38.2)$ & \\
\hline Left main & $24(2.1)$ & $57(1.4)$ & \\
\hline Multi-vessel disease & $545(48.5)$ & $1845(45.9)$ & 0.119 \\
\hline ACC/AHA B2/C lesion (\%) & $998(88.4)$ & $3594(89.0)$ & 0.566 \\
\hline IRA stent diameter, mm & $3.15 \pm 0.43$ & $3.18 \pm 0.42$ & 0.081 \\
\hline IRA stent length, mm & $25.59 \pm 7.22$ & $25.28 \pm 7.14$ & 0.190 \\
\hline \multicolumn{4}{|l|}{ TIMI flow grade (\%) } \\
\hline Initial TIMI flow 0/1 & $836(74.0)$ & $3001(74.3)$ & 0.854 \\
\hline Final TIMI flow 3 & $1096(97.1)$ & $3903(96.7)$ & 0.481 \\
\hline \multicolumn{4}{|l|}{ Medical treatment (\%) } \\
\hline Aspirin & $1129(100)$ & $4028(99.8)$ & 0.094 \\
\hline \multicolumn{4}{|l|}{ P2Y12 receptor inhibitor } \\
\hline Clopidogrel & $738(65.4)$ & $2392(59.2)$ & $<0.001$ \\
\hline Ticagrelor & $264(23.4)$ & $1009(25.0)$ & 0.274 \\
\hline Prasugrel & $127(11.2)$ & $637(15.8)$ & $<0.001$ \\
\hline Statins & $1071(94.9)$ & $3703(91.7)$ & $<0.001$ \\
\hline ACEI/ARB & $901(79.8)$ & 3187 (78.9) & 0.530 \\
\hline Beta-blockers & $980(86.8)$ & $3439(85.2)$ & 0.167 \\
\hline Calcium channel blockers & $42(3.7)$ & $127(3.1)$ & 0.337 \\
\hline
\end{tabular}

Data are expressed as No. (\%) unless otherwise indicated.

ACC: American College of Cardiology, AHA: American Heart Association, ACEI: angiotensin-converting enzyme inhibitor, ARB: angiotensin II receptor blocker, IRA: infarct-related artery, TIMI: thrombolysis in myocardial infarction.

\section{Clinical outcomes}

In the endpoint of survival outcomes in Fig. 2. KaplanMeier curves showed that the cumulative rate of MACCEs in the previous angina group was lower than in the control group ( $4.9 \%$ vs. $8.0 \%$, log-rank, $p=0.012$ ). Furthermore, for the cumulative rate of all cause death and cardiac death the previous angina group was also lower than the control group $(6.2 \%$ vs. $8.6 \%$, log-rank, $\mathrm{p}=0.012$ and $4.1 \%$ vs. $6.6 \%$, log-rank, $\mathrm{p}=0.002$; respectively).

The univariate analysis is shown the Table 3 . We selected a large number of factors to predict adverse factors, and analysis by the COX proportional hazard ratio analysis revealed that previous angina (HR, 0.81, 95\% CI, 0.68$0.95, \mathrm{p}=0.012$ ) was a risk factor for adverse cardiac events. However, being over 65 years, a male, with a history of hypertension, DM, low blood pressure, high heart rate, high BMI, high Killip class, a history of PCI, heart failure and CVA, smoking, low levels of hemoglobin and low HDL-cholesterol, low glomerular filtration rate (GFR), high levels of triglycerides, high LDL-cholesterol, and HbA1c, high door-to-balloon time, high-type lesion, slow post thrombolysis in myocardial infarction (TIMI) flow, and multivessel disease were all independent predictive factors for adverse cardiac events. According to multivariate analysis, previous angina ( $\mathrm{HR}, 0.76,95 \% \mathrm{CI}, 0.60-0.96, \mathrm{p}=0.019)$ was a negative risk factor for adverse cardiac events. Moreover, age over 65 years (HR, 1.51, 95\% CI, 1.22-1.86, $\mathrm{p}<0.001)$, high heart rate (HR, 1.74, 95\% CI, 1.34-2.25, p<0.001), high Killip class (HR, 1.44, 95\% CI, 1.10-1.88, p=0.007), low levels of hemoglobin (HR, 1.57, 95\% CI, 1.06-2.32, $\mathrm{p}=0.024$ ), low levels of HDL-cholesterol (HR, 1.26, 95\% CI, 1.05-1.52, $\mathrm{p}=0.014$ ), high levels of LDL-cholesterol (HR, 0.78, 95\% CI, 0.60-1.00, p=0.050), low GFR (HR, 1.68, 95\% CI, 1.36-2.07, $\mathrm{p}<0.001$ ), slow post TIMI flow (HR, 0.57, 95\% CI, 0.38-0.85, $\mathrm{p}=0.006)$ and multivessel disease (HR, 1.78, 95\% CI, 1.47$2.15, \mathrm{p}<0.001$ ) were all prognostic factors for MACCE.

The COX regression unadjusted and adjusted survival analysis is shown in Table 4. Unadjusted survival analysis revealed that all-cause death and cardiac death rates were statistically significant (HR, 0.71, 95\% CI, 0.55-0.91, p=0.008 and HR, $0.61,95 \% \mathrm{CI}, 0.45-0.83$, $\mathrm{p}=0.002$, respectively), as well as MACCE rates (HR, 0.81, 95\% CI, 0.69-0.95, $\mathrm{p}=0.012$ ). In adjusted analysis, at the 2-year clinical follow-up, MACCE had occurred in 168 (14.9\%) patients in the previous-angina group and in $756(18.0 \%)$ patients in the control group (HR, 0.76, 95\% CI, 0.60-0.96, p=0.019). Percentage all-cause death rates were $6.2 \%$ (70 patients) in the previous-angina group and $8.6 \%$ (349 patients) in the control group (HR, 0.65, 95\% CI, 0.44-0.96, p=0.029). Percentage cardiac death rates were $4.1 \%$ (46 patients) in the previous-angina group and $6.6 \%$ (266 patients) in the control group (HR, 0.52, 95\% CI, 0.31-0.84, p=0.008). Rates of recurrent myocardial infarction, repeat PCI, CABG, and CVA in the two groups were not statistically significant. 


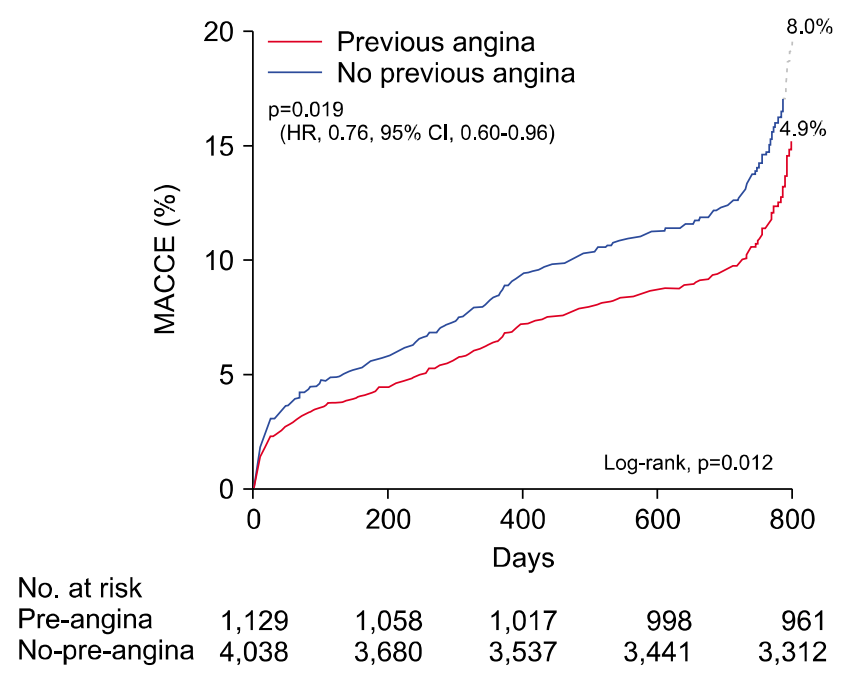

Previous angina
No previous angina
$\begin{aligned} & \text { No. at risk } \\ & \text { Pre-angina } \\ & \text { No-pre-angina }\end{aligned}$

\section{DISCUSSION}

In this study, we found that patients with STEMI treated by insertion of DESs who had experienced previous angina had a lower incidence of MACCE than control patients without previous angina in 2-year (800-day) outcomes; patients were selected from the KAMIR-NIH registry, which is a prospective multi-center cohort study.

IPC has been initiated in many clinical disease areas, including ischemic heart disease, stroke, cardiac surgery, transplantation, and acute kidney injury, and has demonstrated many potentially beneficial effects. ${ }^{10}$ However, it has not been recommended for routine use unless there is more extensive high-quality evidence of its benefits. In 1986, Murry first discovered that one or more short-course incidences of coronary ischemia could protect the myocardium from subsequent long-term ischemia. ${ }^{2,11}$ In a clinical setting, varying degrees of ischemia in an AMI can lead to adaptive loss of congenital heart protection in different regions of the ischemic myocardium, such as IPC and posttreatment. ${ }^{12}$ This heterogeneity may lead to uncertain results in clinical research.

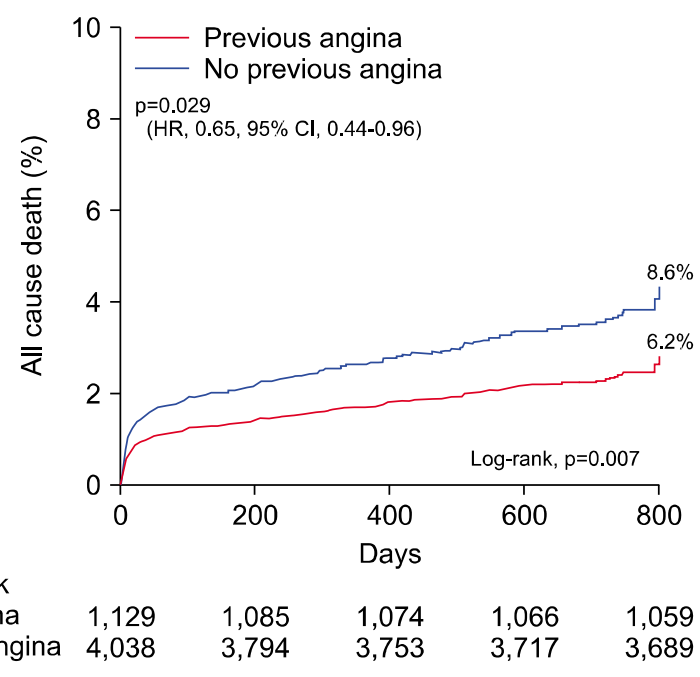

FiG. 2. Adjusted cumulative incidences of MACCE, all-cause death and cardiac death. MACCE: major adverse cardiac and cerebrovascular events, pre-angina: previous angina.

Theoretically, IPC is associated with previous angina, that is, unstable angina before AMI. Known previous angina has better clinical outcomes than sudden AMI without previous. ${ }^{13}$ The detection of previous angina has been an important part of cardiac assessment. In the past, it has been seen as a warning to assess whether patients have severe coronary artery disease. ${ }^{1,14}$ However, it may be a corollary of IPC in humans ${ }^{15}$ and represents a transient ischemic attack before MI. This is similar to the transient reversible ischemic attack that triggers preconditioning in animal studies. ${ }^{16}$ However, a large multicenter study of remote IPC for heart surgery, showed no reduction in remote ischemic preconditioning (RIPC) and adverse reactions to cardiac and brain events. ${ }^{17}$

Interestingly, factors such as hypertension, left ventricular hypertrophy, hyperlipidemia, diabetes, and age and gender may increase, weaken, or even eliminate the protection provided by IPC. ${ }^{18}$ Although there is some evidence for the above, conclusive proof has not been provided so far. However, it has been determined that some of the most common drug treatments for cardiovascular risk factors may alter the cardioprotective effects of IPC. ${ }^{19}$ Aspirin, 
TABLE 3. Univariate and multivariate analysis for predictors of MACCE

\begin{tabular}{|c|c|c|c|c|}
\hline & \multicolumn{2}{|c|}{ Univariate analysis } & \multicolumn{2}{|c|}{ Multivariate analysis } \\
\hline & HR $(95 \% \mathrm{CI})$ & p-value & $\mathrm{HR}(95 \% \mathrm{CI})$ & $\mathrm{p}$-value \\
\hline Pre-angina & $0.81(0.68-0.95)$ & 0.012 & $0.76(0.60-0.96)$ & 0.019 \\
\hline Age $\geq 65$ years & $2.03(1.78-2.32)$ & $<0.001$ & $1.51(1.22-1.86)$ & $<0.001$ \\
\hline Male sex & $0.70(0.61-0.82)$ & $<0.001$ & $0.86(0.65-1.15)$ & 0.306 \\
\hline Hypertension & $1.49(1.30-1.70)$ & $<0.001$ & $1.18(0.97-1.43)$ & 0.092 \\
\hline $\mathrm{DM}$ & $1.65(1.44-1.90)$ & $<0.001$ & $1.14(0.89-1.46)$ & 0.299 \\
\hline $\mathrm{SBP}<90, \mathrm{mmHg}$ & $2.56(2.12-3.08)$ & $<0.001$ & $1.16(0.84-1.59)$ & 0.379 \\
\hline Heart rate $>100$, beat $/ \mathrm{min}$ & $2.34(1.97-2.77)$ & $<0.001$ & $1.74(1.34-2.25)$ & $<0.001$ \\
\hline $\mathrm{BMI} \geq 25, \mathrm{~kg} / \mathrm{m}^{2}$ & $0.78(0.67-0.90)$ & 0.001 & $0.93(0.76-1.14)$ & 0.505 \\
\hline Killip III/IV & $3.02(2.61-3.49)$ & $<0.001$ & $1.44(1.10-1.88)$ & 0.007 \\
\hline History of $\mathrm{HF}$ & $3.46(2.11-5.67)$ & $<0.001$ & $1.95(1.03-3.70)$ & 0.041 \\
\hline History of CVA & $2.12(1.69-2.66)$ & $<0.001$ & $1.35(0.98-1.86)$ & 0.068 \\
\hline Current smoking & $0.75(0.66-0.85)$ & $<0.001$ & $1.07(0.85-1.34)$ & 0.580 \\
\hline $\mathrm{Hb}<10, \mathrm{~g} / \mathrm{dL}$ & $3.11(2.37-4.06)$ & $<0.001$ & $1.57(1.06-2.32)$ & 0.024 \\
\hline $\mathrm{GFR} \leq 60, \mathrm{~mL} / \mathrm{min}$ & $2.67(2.33-3.06)$ & $<0.001$ & $1.68(1.36-2.07)$ & $<0.001$ \\
\hline Triglycerides $\geq 150, \mathrm{mg} / \mathrm{dL}$ & $0.83(0.71-0.97)$ & 0.017 & $0.96(0.78-1.19)$ & 0.723 \\
\hline HDL-cholesterol $\leq 40, \mathrm{mg} / \mathrm{dL}$ & $1.34(1.16-1.53)$ & $<0.001$ & $1.26(1.05-1.52)$ & 0.014 \\
\hline LDL-cholesterol $\geq 70, \mathrm{mg} / \mathrm{dL}$ & $0.57(0.47-0.69)$ & $<0.001$ & $0.78(0.60-1.00)$ & 0.050 \\
\hline $\mathrm{HbA} 1 \mathrm{c}>6.5 \%$ & $1.35(1.14-1.60)$ & 0.001 & $1.01(0.79-1.29)$ & 0.925 \\
\hline Door-to-balloon time $\geq 90$, $\min$ & $1.33(1.12-1.58)$ & 0.002 & $1.11(0.86-1.43)$ & 0.420 \\
\hline Post TIMI 0/1 & $0.49(0.37-0.65)$ & $<0.001$ & $0.57(0.38-0.85)$ & 0.006 \\
\hline Multivessel disease & $2.15(1.87-2.46)$ & $<0.001$ & $1.78(1.47-2.15)$ & $<0.001$ \\
\hline
\end{tabular}

Cl: confidence interval, CVA: cerebrovascular accident, IRA: infarct-related artery, LM: left main, LAD: left anterior descending, LCX: left circumflex, LDL: low-density lipoprotein, GFR: glomerular filtration rate, HR: hazard ratio, HF: heart failure, Hb: hemoglobin, HDL: high-density lipoprotein, RCA: right coronary artery, TIMI: thrombolysis in myocardial infarction, Pre-angina: previous angina.

TABLE 4. Unadjusted and adjusted clinical outcomes at 2 years of the two groups

\begin{tabular}{|c|c|c|c|c|c|c|}
\hline Variables & $\begin{array}{c}\text { Pre-angina } \\
(\mathrm{n}=1129)\end{array}$ & $\begin{array}{l}\text { No-pre-angina } \\
\quad(\mathrm{n}=4038)\end{array}$ & $\begin{array}{l}\text { Unadjusted } \\
\text { HR }(95 \% \text { CI })\end{array}$ & p-value & $\begin{array}{c}\text { Adjusted } \\
\text { HR }(95 \% \text { CL })\end{array}$ & $\mathrm{p}$-value \\
\hline \multicolumn{7}{|c|}{ Clinical outcomes $(\%)$} \\
\hline All-cause death & $70(6.2)$ & $349(8.6)$ & $0.71(0.55-0.91)$ & 0.008 & $0.65(0.44-0.96)$ & 0.029 \\
\hline Cardiac death & $46(4.1)$ & $266(6.6)$ & $0.61(0.45-0.83)$ & 0.002 & $0.52(0.31-0.84)$ & 0.008 \\
\hline Recurrent MI & $20(1.8)$ & $90(2.2)$ & $0.77(0.48-1.25)$ & 0.293 & $0.59(0.31-1.15)$ & 0.119 \\
\hline Repeat PCI & $79(7.0)$ & $292(7.2)$ & $0.94(0.74-1.21)$ & 0.644 & $0.95(0.69-1.32)$ & 0.775 \\
\hline TLR & $19(1.7)$ & $67(1.7)$ & $0.99(0.60-1.65)$ & 0.969 & $1.09(0.58-2.03)$ & 0.806 \\
\hline TVR & $40(3.5)$ & $131(3.2)$ & $1.07(0.75-1.52)$ & 0.710 & $1.10(0.71-1.71)$ & 0.672 \\
\hline CABG & $3(0.3)$ & $18(0.4)$ & $0.58(0.17-1.98)$ & 0.385 & $0.75(0.20-2.79)$ & 0.670 \\
\hline CVA & $24(2.1)$ & $80(2.0)$ & $1.03(0.65-1.62)$ & 0.903 & $0.75(0.40-1.42)$ & 0.375 \\
\hline MACCE & $168(14.9)$ & $726(18.0)$ & $0.81(0.69-0.95)$ & 0.012 & $0.76(0.60-0.96)$ & 0.019 \\
\hline
\end{tabular}

Data are expressed as No. (\%) unless otherwise indicated.

CVA: cerebrovascular accident, CABG: coronary artery bypass graft, MI: myocardial infarction, MACCE: major adverse cardiac and cerebrovascular events, PCI: percutaneous coronary intervention, TLR: target lesion revascularization, TVR: target vessel revascularization.

which blocks COX-2, which is involved in the protective signals to IPC, interferes with endogenous cardio-protection. ${ }^{20}$

Kobayashi et al. ${ }^{5}$ reported that lower incidence of in-hospital death in patients with previous angina was due to lower occurrence of cardiac rupture in patients who had experienced their first AMI. Moreover, the results of TIMI $4^{21}$ and TIMI $2^{22}$ suggest that the incidence of cardiogenic shock is low and there are no significant differences in previous angina groups and control groups. There are many predictors of MACCE outcomes, and previous angina is an independent predictor of outcome (HR, 0.76, 95\% CI, 0.60-0.96, $\mathrm{p}=0.019$ ). We observed that, consistent with their results, our results revealed a smaller incidence of cardiovascular events in patients in the pre-angina group than in those in the control group.

According to previous studies, patients with previous angina have a lower mortality rate due to heart rupture. Hirai et al. ${ }^{23}$ believed this to be due to the presence of collat- 
eral circulation in patients with previous angina pectoris. It has also been reported that coronary collateral circulation prevents heart rupture. Moreover, Radford et al. ${ }^{24}$ studied the possibility that the proportion of previous-angina patients who are male is greater than those who are female, because men have a lower incidence of heart rupture than women. Although more than half of the patients in our study were men $(>75 \%)$, our results are similar, and the true mechanism is not clear.

It is difficult to compare mortality rates in the two groups because patients with previous angina cannot confirm whether they have had an MI before. Although our base data showed previous MI in 237 patients (4.6\%), it is unclear except for them. Furthermore, we did not exclude these patients from our study, which may have been better practice. The protective effects of previous angina have usually been attributed to induced ischemic preconditioning, which acts by inducing metabolic changes in myocardial cells that make them more resistant to a subsequent severe ischemic insult. ${ }^{3}$ In general, patients with previous symptoms of angina are expected to have a history of taking aspirin or clopidogrel for a long time, so their prognosis should be better than that of patients without previous angina, and this is reflected by our results. Furthermore, other studies have been suggested to contribute to the favorable effects of previous angina. These patients, indeed, have been shown to present more evident collateral circulation compared to patients without previous angina. ${ }^{25}$

There are several limitations to this study. First, we only selected patients with previous angina as patients with IPC; we cannot be certain if they were protected by IPC. It is possible that some patients were not protected by IPC, as this protection is lost after a few hours, as was evident in the canine experiment. ${ }^{2}$ Secondly, we did not distinguish between the length of time intervals when investigating MACCE (e.g., 1-week, 1-month or 1-year after MACCE occurred in the two groups), because certain studies have shown that their cardiovascular time rates vary over time. ${ }^{26}$ Finally, we did not conduct a randomized controlled trial; we need to study additional patients for longer time frames to achieve more accurate results.

In summary, we found that prognosis improved in the 2-year clinical follow-up analysis in STEMI patients with previous angina in whom DESs where inserted than in patients without previous angina. Previous angina pectoris is an independent, negative risk factor for MACCE outcomes. Clinically, we should be more vigilant and closely observe STEMI patients without previous angina for changes to their conditions.

\section{ACKNOWLEDGEMENTS}

We would like to thank all Korea Acute Myocardial Infarction Registry-National Institutes of Health (KAMIR$\mathrm{NIH}$ ) investigators.

Myung Ho Jeong, MD; Youngkeun Ahn, MD; Sung Chul Chae, MD; Jong Hyun Kim, MD; Seung-Ho Hur, MD;
Young Jo Kim, MD; In Whan Seong, MD; Donghoon Choi, MD; Jei Keon Chae, MD; Taek Jong Hong, MD; Jae Young Rhew, MD; Doo-Il Kim, MD; In-Ho Chae, MD; Jung Han Yoon, MD; Bon-Kwon Koo, MD; Byung-Ok Kim, MD; Myoung Yong Lee, MD; Kee-Sik Kim, MD; Jin-Yong Hwang, MD; Myeong Chan Cho, MD; Seok Kyu Oh, MD; Nae-Hee Lee, MD; Kyoung Tae Jeong, MD; Seung-Jea Tahk, MD; Jang-Ho Bae, MD; Seung-Woon Rha, MD; Keum-Soo Park, MD; Chong Jin Kim, MD; Kyoo-Rok Han, MD; Tae Hoon Ahn, MD; Moo-Hyun Kim, MD; Ki Bae Seung, MD; Wook Sung Chung, MD; Ju-Young Yang, MD; Chong Yun Rhim, MD; Hyeon-Cheol Gwon, MD; SeongWook Park, MD; Young-Youp Koh, MD; Seung Jae Joo, MD; Soo-Joong Kim, MD; Dong Kyu Jin, MD; Jin Man Cho, MD; Sang-Wook Kim, MD; Jeong Kyung Kim, MD; Tae Ik Kim, MD; Deug Young Nah, MD; Si Hoon Park, MD; Sang Hyun Lee, MD; Seung Uk Lee, MD; Hang-Jae Chung, MD; Jang-Hyun Cho, MD; Seung Won Jin, MD; Myeong-Ki Hong, MD; Yangsoo Jang, MD; Jeong Gwan Cho, MD; Hyo-Soo Kim, MD; and Seung Jung Park, MD.

The research was supported by a fund (2016 - ER6304 02) by research of Korea centers for disease control and prevention.

\section{CONFLICT OF INTEREST STATEMENT}

None declared.

\section{REFERENCES}

1. Rezkalla SH, Kloner RA. Ischemic preconditioning and preinfarction angina in the clinical arena. Nat Clin Pract Cardiovasc Med 2004;1:96-102.

2. Murry CE, Jennings RB, Reimer KA. Preconditioning with ischemia: a delay of lethal cell injury in ischemic myocardium. Circulation 1986;74:1124-36.

3. Ottani F, Galvani M, Ferrini D, Sorbello F, Limonetti P, Pantoli $\mathrm{D}$, et al. Prodromal angina limits infarct size. A role for ischemic preconditioning. Circulation 1995;91:291-7.

4. Herrett E, Bhaskaran K, Timmis A, Denaxas S, Hemingway H, Smeeth L. Association between clinical presentations before myocardial infarction and coronary mortality: a prospective population-based study using linked electronic records. Eur Heart J 2014;35:2363-71.

5. Kobayashi Y, Miyazaki S, Itoh A, Daikoku S, Morii I, Matsumoto T, et al. Previous angina reduces in-hospital death in patients with acute myocardial infarction. Am J Cardiol 1998;81:117-22.

6. Anzai T, Yoshikawa T, Asakura Y, Abe S, Akaishi M, Mitamura $\mathrm{H}$, et al. Preinfarction angina as a major predictor of left ventricular function and long-term prognosis after a first $\mathrm{Q}$ wave myocardial infarction. J Am Coll Cardiol 1995;26:319-27.

7. Stefanini GG, Holmes DR Jr. Drug-eluting coronary-artery stents. N Engl J Med 2013;368:254-65.

8. Sim DS, Jeong MH. Differences in the Korea acute myocardial infarction registry compared with Western registries. Korean Circ J 2017;47:811-22.

9. Kim JH, Chae SC, Oh DJ, Kim HS, Kim YJ, Ahn Y, et al. Multicenter 
cohort study of acute myocardial infarction in Korea - interim analysis of the Korea Acute Myocardial Infarction RegistryNational Institutes of Health registry. Circ J 2016;80:1427-36.

10. Sukkar L, Hong D, Wong MG, Badve SV, Rogers K, Perkovic V, et al. Effects of ischaemic conditioning on major clinical outcomes in people undergoing invasive procedures: systematic review and meta-analysis. BMJ 2016;355:i5599.

11. Cave A, Garlick P. Re: Preconditioning with ischemia: a delay of lethal cell injury in ischemic myocardium. J Mol Cell Cardiol 2000; 32:1759-60.

12. Yellon DM, Hausenloy DJ. Myocardial reperfusion injury. N Engl J Med 2007;357:1121-35.

13. Ferdinandy P, Hausenloy DJ, Heusch G, Baxter GF, Schulz R. Interaction of risk factors, comorbidities, and comedications with ischemia/reperfusion injury and cardioprotection by preconditioning, postconditioning, and remote conditioning. Pharmacol Rev 2014;66:1142-74.

14. Heusch G. Nitroglycerin and delayed preconditioning in humans: yet another new mechanism for an old drug? Circulation 2001; 103:2876-8.

15. Kloner RA, Jennings RB. Consequences of brief ischemia: stunning, preconditioning, and their clinical implications: part 2. Circulation 2001;104:3158-67.

16. Heusch G, Bøtker HE, Przyklenk K, Redington A, Yellon D. Remote ischemic conditioning. J Am Coll Cardiol 2015;65:177-95.

17. Meybohm P, Bein B, Brosteanu O, Cremer J, Gruenewald M, Stoppe $\mathrm{C}$, et al. A multicenter trial of remote ischemic preconditioning for heart surgery. N Engl J Med 2015;373:1397-407.

18. Schwartz Longacre L, Kloner RA, Arai AE, Baines CP, Bolli R, Braunwald E, et al. New horizons in cardioprotection: recommendations from the 2010 National Heart, Lung, and Blood Institute Workshop. Circulation 2011;124:1172-9.
19. Stokfisz K, Ledakowicz-Polak A, Zagorski M, Zielinska M. Ischaemic preconditioning - current knowledge and potential future applications after 30 years of experience. Adv Med Sci 2017; 62:307-16.

20. Przyklenk K, Heusch G. Late preconditioning against myocardial stunning. Does aspirin close the "second window" of endogenous cardioprotection? J Am Coll Cardiol 2003;41:1195-7.

21. Kloner RA, Shook T, Przyklenk K, Davis VG, Junio L, Matthews RV, et al. Previous angina alters in-hospital outcome in TIMI 4. A clinical correlate to preconditioning? Circulation 1995;91:3745.

22. Ruocco NA Jr, Bergelson BA, Jacobs AK, Frederick MM, Faxon DP, Ryan TJ. Invasive versus conservative strategy after thrombolytic therapy for acute myocardial infarction in patients with antecedent angina. A report from Thrombolysis in Myocardial Infarction Phase II (TIMI II). J Am Coll Cardiol 1992;20:1445-51.

23. Hirai T, Fujita M, Yamanishi K, Ohno A, Miwa K, Sasayama S. Significance of preinfarction angina for preservation of left ventricular function in acute myocardial infarction. Am Heart $\mathrm{J}$ 1992;124:19-24.

24. Radford MJ, Johnson RA, Daggett WM Jr, Fallon JT, Buckley MJ, Gold HK, et al. Ventricular septal rupture: a review of clinical and physiologic features and an analysis of survival. Circulation 1981; 64:545-53.

25. Traupe T, Gloekler S, de Marchi SF, Werner GS, Seiler C. Assessment of the human coronary collateral circulation. Circulation 2010;122:1210-20.

26. Sloth AD, Schmidt MR, Munk K, Kharbanda RK, Redington AN, Schmidt M, et al. Improved long-term clinical outcomes in patients with ST-elevation myocardial infarction undergoing remote ischaemic conditioning as an adjunct to primary percutaneous coronary intervention. Eur Heart J 2013;35:168-75. 